\title{
SMALL RENAL MASS WITH MULTIPLE PARA-AORTIC LYMPHADENOPATHY- A CASE REVEALING THE HISTOLOGICAL MYSTERY
}

Kiran H. S1

${ }^{1}$ Assistant Professor, Department of Pathology, Yenepoya Medical College, Mangalore.

\section{ABSTRACT}

\section{BACKGROUND}

The association of renal adenocarcinoma and tuberculosis is uncommon.[1] While the incidental discovery of Renal Cell Carcinoma (RCC) in a tuberculous kidney is well-described, the discovery of tuberculous lesions after nephrectomy for cancer is exceptional.[1] We report here a case of 54-year-old female who came to our hospital presenting with small renal lesion with tumour suspicion along with multiple hilar and para-aortic lymphadenopathy without having any other comorbid illness underwent laparoscopic radical nephrectomy. On histopathological examination, the renal lesion turned out into concurrent conventional renal cell carcinoma with multiple foci of granulomatous reaction in the renal parenchyma with characteristic granulomas comprising Langhans giant cells, which was suggestive of tuberculous nephritis. In support to this, the multiple hilar and para-aortic regional lymph nodes showed features of tuberculous lymphadenitis with extensive areas of caseating granulomas with Langhans giant cells, following which the PCR studies confirmed the diagnosis of tuberculosis.

\section{KEYWORDS}

Carcinoma, Granuloma, Tuberculosis.

HOW TO CITE THIS ARTICLE: Kiran HS. Small renal mass with multiple para-aortic lymphadenopathy - a case revealing the histological mystery. J. Evolution Med. Dent. Sci. 2017;6(17):1386-1387, DOI: 10.14260/Jemds/2017/302

\section{BACKGROUND}

The association of renal tuberculosis and renal cancer is exceptional; less than fifty cases have been reported in the literature.[2] We hereby report a case of adult lady presented with a small renal mass and multiple para-aortic lymphadenopathy establishing the association of renal cell carcinoma with tuberculosis.

\section{Case Report}

A female patient aged 54 years without any co-morbid illness was incidentally detected to have a renal tumour. CT urogram revealed a $39 \times 34 \mathrm{~mm}$, exophytic, solid, enhancing lesion with necrotic area within the left kidney with multiple enlarged para-aortic and left renal lymph nodes. There was no obvious abnormality in the rest of the parenchyma of the urinary tract. A laparoscopic radical nephrectomy was performed, during which multiple enlarged lymph nodes were seen in the renal and para-aortic region (Figure 1). The entire specimen was sent for histopathology.

Grossly, the kidney appeared enlarged with $10 * 6 * 1 \mathrm{cms}$ weighing 155 gms. A nodular growth was seen on the anterior surface of kidney with cut surface showing firm and variegated appearance located $4.8 \mathrm{cms}$ from the superior pole and $4 \mathrm{~cm}$ from the inferior pole measuring $4 * 4 * 1 \mathrm{~cm}$ with intact capsule. The renal vessels, renal pelvis, ureter and adrenal gland grossly appeared free from the tumour. Microscopically, tumour tissue showed tumour cells in sheets and nests separated by thin fibrovascular septae. These cells had abundant clear to granular cytoplasm with centrally placed hyperchromatic nuclei and few having prominent nucleoli. Surprisingly, on meticulous examination there were

Financial or Other, Competing Interest: None.

Submission 19-01-2017, Peer Review 11-02-2017,

Acceptance 18-02-2017, Published 27-02-2017.

Corresponding Author

Dr. Kiran H. S

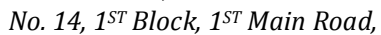

Shakthi Nagar, Mysore-570019.

E-mail: drkiranhs22@gmail.com

DOI: $10.14260 /$ jemds $/ 2017 / 302$ seen vaguely formed granulomas with collection of epithelioid histiocytes, lymphocytes and fibroblasts with characteristic Langhans giant cells in the renal parenchyma. In addition to this all the fifteen hilar and para-aortic lymph nodes showed caseating granulomas with Langhans giant cells and extensive areas of caseous necrosis without any evidence of tumour deposits.

On histopathology, it was reported as conventional clear cell carcinoma (Figure 2, 3), Fuhrman grade II with tuberculous nephritis. The surrounding renal parenchyma adjacent to the tumour showed granulomas with Langhans giant cells (Figure 4,5). The margins and perirenal fat removed, ureter and hilar vessels were free from the tumour. The para-aortic lymph nodes showed features of granulomatous lymphadenitis with no tumour metastasis suggestive of tuberculous lymphadenitis (Figure 6, 7).

The search for tubercular bacilli performed in urine and sputum after surgery was negative. Neither of the preoperative chest radiographs showed any signs of tuberculosis. PCR studies yielded and supported the diagnosis of tuberculosis. A quadruple anti-tubercular regimen was subsequently started.

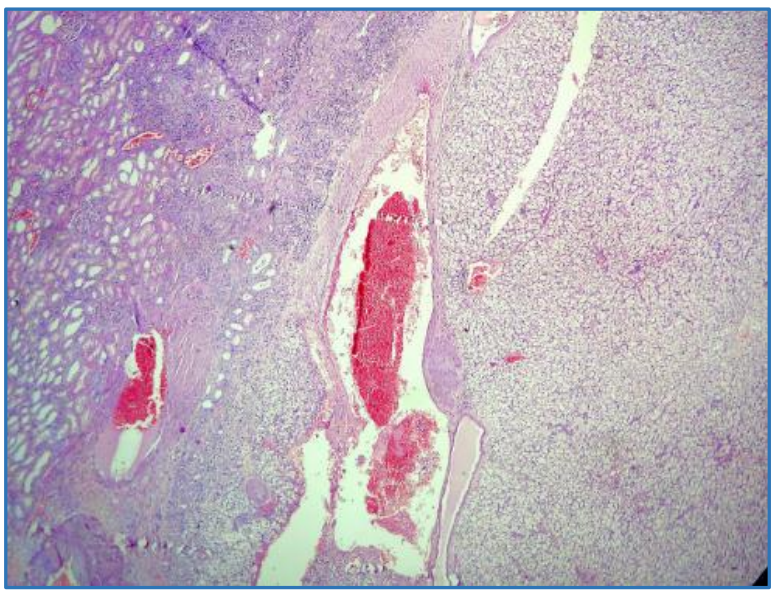

Figure 1. Low Power View of Tumour Cells (Clear Cell Carcinoma) (10X) H \& E 


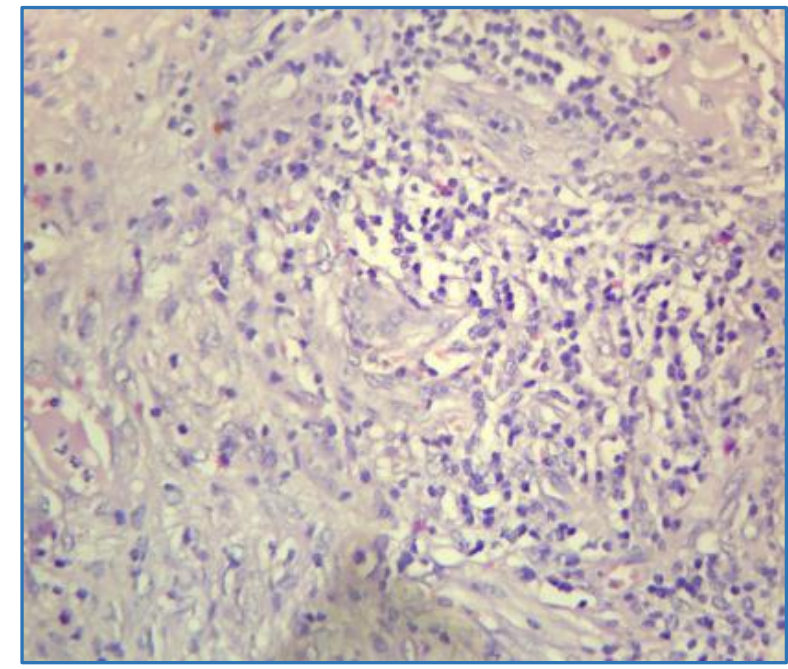

Figure 2. High Power View of Tuberculous Nephritis (45X) H \& E

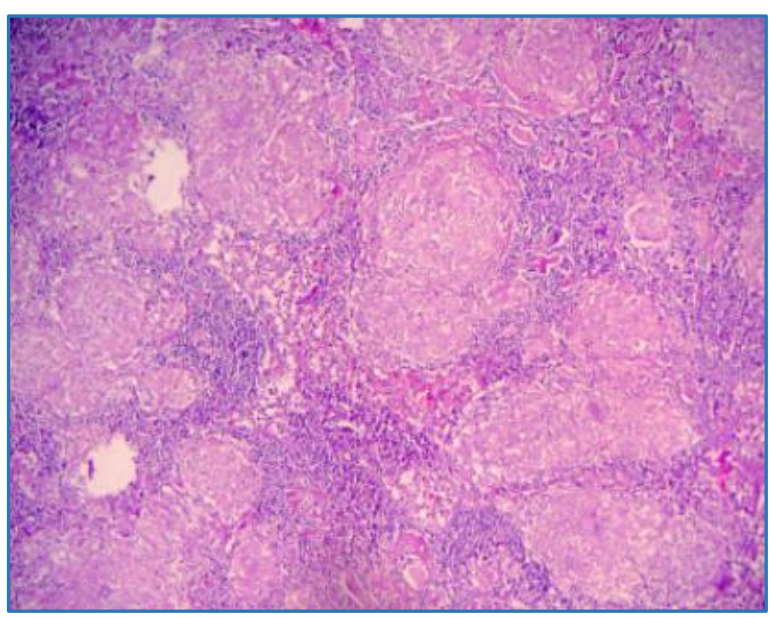

Figure 3. Low Power View of Lymph Node showing Granulomas with Caseous Necrosis (10X) H \& E

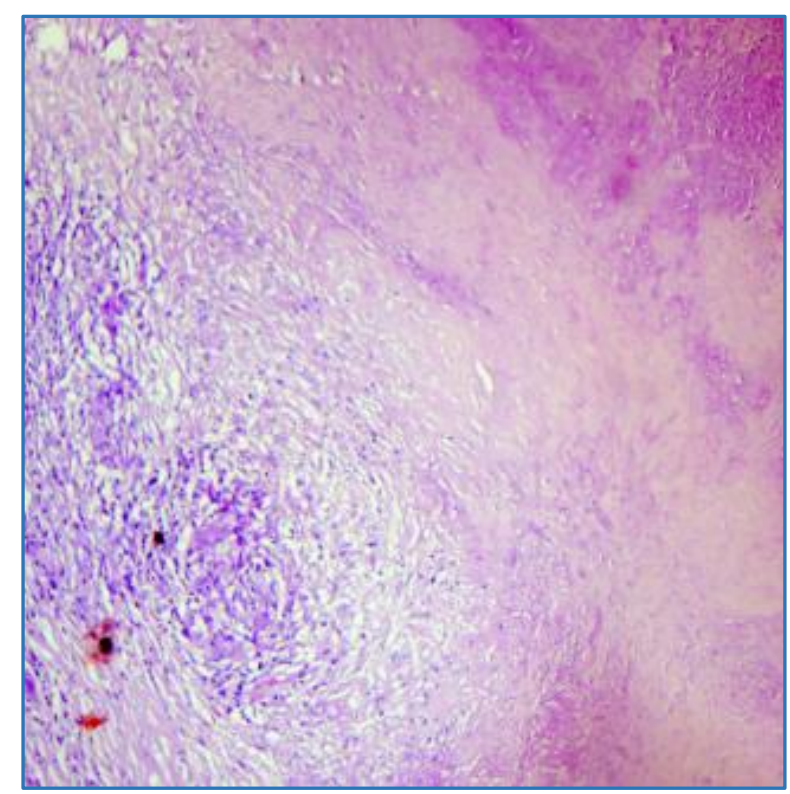

Figure 4. Low Power View of Lymph Nodes showing Granulomas with Large Area of Caseous Necrosis (10X) H $\& E$

\section{DISCUSSION}

In our case, it was clinically a small renal tumour with lymph node metastasis, which was later diagnosed to have associated tuberculous lesions. The patient had no known history of mycobacterial infection. To our knowledge, only few cases of accidental discovery of isolated renal tuberculosis have been reported in the literature. Authors have reported that kidney cancer occurs in $0.2 \%$ of cases of renal tuberculosis.[3] There is a high frequency of this association in the Mediterranean region. ${ }^{[3]}$ The age of onset of this association according to published cases is between 50 and 70 years with male predominance. ${ }^{[4]}$ For most authors this association could be related to reactivation of latent tuberculosis secondary to local immunosuppression induced by the tumour.[5] The conventional clear cell carcinoma is the histological form, which is predominantly found associated with renal tuberculosis. ${ }^{3,4}$ Cancer treatment on renal tuberculous nephritis is based on the radical nephrectomy, this one can only be achieved after impregnation with a TB treatment for at least four weeks to prevent secondary infection and spread of Mycobacterium tuberculosis. Presently, conservative surgery is increasingly performed for tumours of small size.[6]

\section{CONCLUSION}

The originality of our observation is based on the double chance discovery of a tumour of the kidney and renal tuberculosis. The concomitant occurrence of renal tuberculosis and renal tumours is rare, the possibility of concurrence should be kept in mind especially in patients with small renal masses with lymph nodal mass, especially from tuberculosis endemic areas and in patients with equivocal symptoms. Treatment should be adapted to the characteristics of cancer. In case of small tumour polar partial nephrectomy followed or preceded by a TB treatment is possible.

\section{REFERENCES}

[1] Pushkar P, Agarwal A, Sarin A, et al. Concurrent RCC with tuberculous para-aortic lymphadenopathy: a pleasant surprise. Can Urol Assoc J 2015;9(3-4):E210-2.

[2] Neibling HA, Walters W. Adenocarcinoma and tuberculosis of the same kidney: review of the literature and report of seven cases. J Urol 1948;59(6):1022-35.

[3] Redonde CC, Zarranz EJ, Toves RA, et al. Tuberculosis and renal cancer. Actas Urol Esp 1999;23(7):617-20.

[4] Peyromaure M, Sebe P, Darwiche F, et al. Tuberculose rénale et adénocarcinome du rein une association trompeuse. Prog Urol 2002;12:89-91.

[5] Patard JJ, Bouet F, Rioux-Leclercq N, et al. Mécanismes de tolérance immunitaire locale dans les cancers du rein. Prog Urol 2002;12:205-12.

[6] Amine EL, Hamid F, Adil D, et al. Adénocarcinome rénal sur néphrite tuberculeuse. Progrès en Urologie 2005;15:309-11. 